\title{
Turskiløper med kraftsvikt og nedsatt bevissthet
}

\author{
Bevissthetsforstyrrelser kan ha mange forklaringer, og av og til blir \\ enkle årsaker oversett. Vi forteller her om en ung turskiløper som utvik- \\ let en alvorlig indremedisinsk tilstand med dramatiske symptomer. Ikke \\ før betydelige prehospitale ressurser var satt inn og mannen ble under- \\ søkt på sykehus, viste det seg at tilstanden kunne vært enkel å behandle.
}

En mann i slutten av 20-årene var på skitur i fjellet sammen med venner. Været var fint, men snøen var våt og tung, og skituren, som varte i syv timer, ble mer strabasiøs enn de først hadde tenkt. Like før de kom frem til bestemmelsesstedet, endret mannen plutselig atferd - han satte seg ned i snøen og sa at han ikke orket å gå lenger. Vennene prøvde iherdig å få ham til à gå det siste stykket, men han ga uttrykk for at han var helt tom for krefter og ikke klarte mer.

Etter kort tid ble han også uklar, agitert, motorisk urolig og aggressiv. Han var lite samarbeidsvillig, og vennene fryktet han skulle bli nedkjølt, siden han lå og kavet $i$ snøen. På grunn av dårlig mobildekning i området kjørte noen av vennene på ski ned til bebyggelsen og ringte AMK-sentralen for å få hjelp. AMK-sentralen anmodet Hovedredningssentralen om assistanse med redningshelikopter.

Vakthavende anestesilege på redningshelikopteret vurderte tilstanden som uavklart og uten sikker diagnose. Siden det var mistanke om begynnende nedkjøling, ble det bestemt at man skulle hente mannen med redningshelikopter.

Det var fine flyforhold - dagslys, lite vind og temperatur omkring $0^{\circ} \mathrm{C}$. Det var omkring 30 nautiske mil i luftlinje til dit hvor pasienten befant seg, noe som indikerte en flytid på ca. 15 minutter med Sea King redningshelikopter.

Under flyturen fikk personellet opplyst fra redningsledelsen at pasienten var tidligere frisk og at han sammen med venner hadde vært på skitur i syv timer denne dagen. Han hadde drukket betydelige mengder vodka, men ikke spist noe.

Vennene fortalte at han lå $i$ snøen uten å kunne ta seg videre og antok at det var på grunn av utmattelse.

Etter et kort søk ble mannen funnet. Fra helikopteret så man at han lå på ryggen og kavet i snøen. Det var ikke mulig å lande like ved, redningsmannen ble derfor heist ned for å hente ham opp i en trekantsele. Da redningsmannen møtte pasienten nede på bak- ken, var han svært utagerende. Etter en del tid klarte man imidlertid å få såpass kontroll over ham at han kunne heises opp i helikopteret sammen med redningsmannen.

Helikopterlegen fant ikke store avvik ved den første orienterende undersøkelsen, men bemerket at pasienten luktet sterkt av alkohol. Glasgow Coma Scale (GCS) var nedsatt fra normalt 15 til 10 poeng. Delskårene var 4-2-4 (normalt 4-5-6), hvor første del viser at pasienten åpnet øynene ved tilsnakk, andre del at han ikke kommuniserte, men kun stønnet og laget lyder, og siste del at han ikke lokaliserte stimuli på annen måte enn å dra seg unna. Pupillene var like store og reagerte likt på lys. Pasienten var godt kledd, og til tross for 1-2 timer i snøen viste surstoffmetningsmåleren normal verdi på $97 \%$, uten ekstra oksygen. Hjertefrekvensen var 60/min, med god pulsamplitude. Vennene opplyste at pasienten ikke hadde noen sykdommer, ikke brukte medisiner eller var allergisk.

Helikopterlegen vurderte derfor den perifere sirkulasjonen som god. Selv om pasienten nektet å la redningsmannskapet måle temperaturen, anså man hypotermi som lite sannsynlig. Pasientens cerebrale symptomer og utagerende atferd ble derfor tilskrevet alkoholpåvirkningen.

På grunn av kort fly- og transporttid til sykehuset med en lite samarbeidsvillig pasient ble det ikke gjort flere undersøkelser. På grunn av pasientens uro ble det heller ikke lagt venetilgang.

Ved ankomst akuttmottaket ble det gjort videre undersøkelser. Rektaltemperaturen ble målt til $36,4^{\circ} \mathrm{C}\left(36-38^{\circ} \mathrm{C}\right)$, og hypotermi ble dermed utelukket. Det var normale verdier for blodtrykk og puls - 108/60 mm Hg og $80 /$ min. Respirasjonsfrekvensen var vanskelig å fastslå på grunn av pasientens uro og agiterte oppførsel, men han hadde ingen åpenbare problemer med luftveier eller respirasjon. Pasienten fremsto som betydelig alkoholpåvirket. Dette ble senere bekreftet av et blodprøvesvar, som viste et etanolnivå på 2,1\%o.

\author{
Trond Skjelstad \\ trond.skjelstad@gmail.com \\ Akuttmedisinsk avdeling \\ Nordlandssykehuset Bodø

\section{Marte Alsos Sørensen} \\ Akuttmedisinsk avdeling \\ Nordlandssykehuset Bodø
}

\section{Erik Waage Nielsen}

Akuttmedisinsk avdeling

Nordlandssykehuset Bodø

og

Institutt for klinisk medisin

Universitetet i Tromsø

og

Profesjonshøgskolen

Nord universitet, Bodø

og

Institutt for klinisk medisin

Universitetet i Oslo

Engelsk oversettelse på www.tidsskriftet.no 


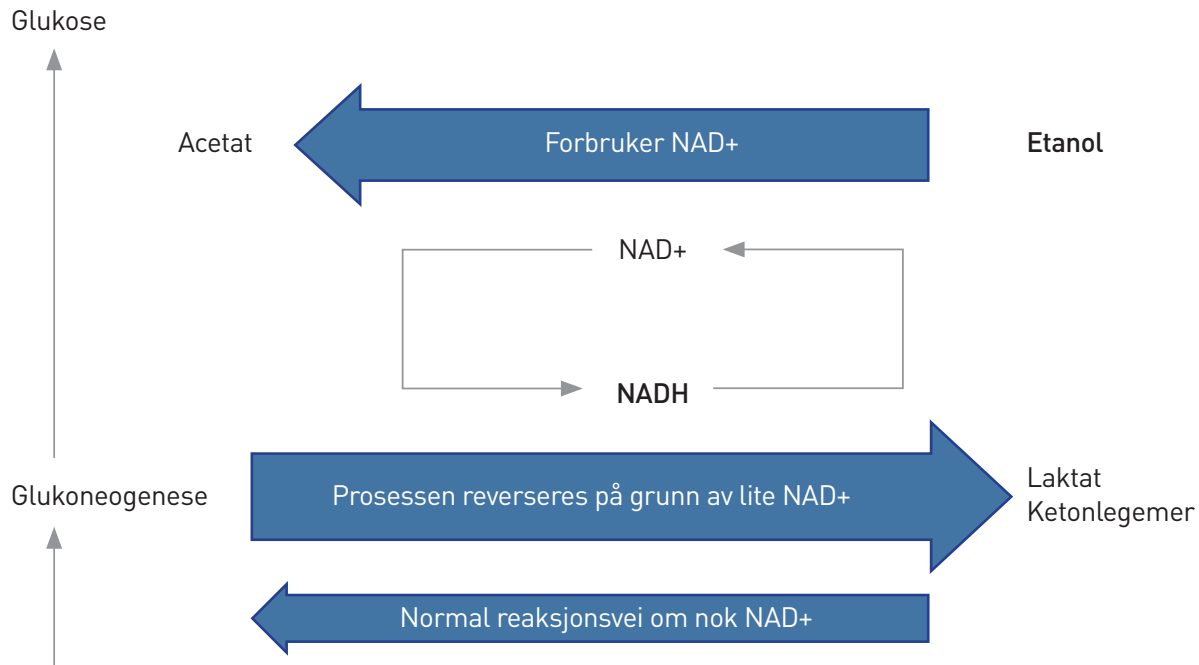

Aminosyrer

Fett

Figur 1 Svært forenklet fremstilling av glukoneogenesen under påvirkning av etanol. For at aminosyrer og fett kan omdannes til glukose i glukoneogenesen trengs blant annet NAD+. Ved etanolpåvirkning forbrukes store mengder NAD+ til metabolisering av etanol. Det gir mindre NAD+ til glukoneogenesen og fører dermed til hypo glykemi. I stedet for at laktat omdannes til glukose, reverseres prosessen og gir økte nivåer av laktat. På grunn av mangel på NAD+ øker også antallet ketonlegemer

Traumelederen i akuttmottaket hadde før ankomsten fått meldt en nedkjølt og beruset pasient. Imidlertid ble hypotermi utelukket etter måling av rektaltemperaturen. Etanolpåvirkning ble initialt vektlagt som forklaring på manglende samarbeidsvilje og unormal oppførsel. Pasienten fortsatte å fekte med armene og rev i både personalet og overvåkningsutstyret.

Det var imidlertid ubesværet respirasjon, og man valgte å avvente sedering og intubasjon.

Blodsukkernivået ble målt iakuttmottaket, og det viste seg å være så lavt som 0,8 mmol/l 13,5-7 mmol/l). Pasienten ble derfor intravenøst gitt flere bolusdoser à $20 \mathrm{ml}$ med $50 \%$ glukose $(500 \mathrm{mg} / \mathrm{ml})$. Etter fire bolusdoser på til sammen $40 \mathrm{~g}$ glukose, og før det var gått 30 minutter, var pasienten rolig, adekvat og kommuniserte normalt. Han snudde seg etter hvert over på siden og sovnet, deretter ble han lagt til overvåkning på intensivavdelingen til neste dag.

Det ble lagt arteriekran. Blodgassmåling viste en betydelig acidose, med $\mathrm{pH}$ på 7,15 (7,35-7,45), $p \mathrm{CO}_{2}$ på 7,6 kPa $(4,7-6 \mathrm{kPa})$, baseoverskudd $-9 \mathrm{mmol} / \mathrm{l}(-3 \mathrm{til}+3 \mathrm{mmol} / \mathrm{ll})$ og laktat 6,6 mmol/l $(0,7-1,8 \mathrm{mmol} / \mathrm{l})$.

Det forelå dermed en kombinert respiratorisk og metabolsk acidose. Hyperkapnien ble tolket som et resultat av at alkoholpåvirkningen etter hvert hadde ført til hypoventilering. Den metabolske acidosen ble i hovedsak funnet å komme fra laktat, selv om det ikke var noen åpenbar laktatkilde. Det var ingen tegn til vevshypoperfusjon, siden blodtrykket var normalt og ekstremitetene velsirkulerte. Det var heller ingen symptomer som ga mistanke om noe patologisk i abdomen.

Det lave blodsukkernivået kom overraskende på legene. Pasienten hadde ingen kjent diabetes mellitus. Det var opplyst av vennene, og senere bekreftet av pasienten selv, at han ikke brukte insulin eller andre medisiner. Siden behandlingen normaliserte de cerebrale symptomene, antok man at hypoglykemi var hovedforklaringen på hele sykdomsforløpet. Årsaken til hypoglykemien ble diskutert, men alkoholindusert hypoglykemi ble på det tidspunktet ikke vurdert.

Etter at pasienten var blitt behandlet for sitt lave blodsukkerninvå, bedret den kliniske situasjonen seg forholdsvis raskt. Etter 3,5 timer viste en blodgassmåling en tilnærmet normal pH på 7,31 (7,35-7,45), pCO 2 på 5,3 kPa $(4,7-6,0 \mathrm{kPa})$, baseoverskudd - $6 \mathrm{mmol} / \mathrm{l}$ (-3 til $+3 \mathrm{mmol} / \mathrm{l})$.

Grunnet den raske bedringen ble det ikke ansett som nødvendig å korrigere acidosen medikamentelt, og pasienten hadde heller ikke behov for ventilasjonsstøtte. Blodgassnivåene normaliserte seg over de neste åtte timer.

Årsaken til den forbigående lactacidosen forble ukjent.
Før utskrivning den påfølgende morgen var alle blodprøver normale.

\section{Diskusjon}

Etanol kan være årsak til hypoglykemi i kombinasjon med faste eller fysisk aktivitet (1). Er det ikke gitt insulin, kan andre årsaker være endogen hyperinsulinemi, perorale antidiabetika, trimetoprim-sulfa, betablokkere, antiarytimika, binyrebarksvikt, sepsis og leversvikt (2).

I en studie fant man at $4 \%$ av etanolintoksikerte hadde hypoglykemi (3). I samme studie ble det referert til en annen amerikansk undersøkelse der det kom frem at etanol skulle være årsaken i $14 \%$ av 1418 medikament- og alkoholutløste hypoglykemiepisoder (2). Disse andelene kan være for høye. Andre har funnet en insidens på 0,9\% (4). Av 2348 pasienter behandlet for akutt forgiftning i Oslo hadde 21 hypoglykemi. Etanol var agens hos 1018 , men en eventuell sammenheng ble ikke diskutert (5). Ved et stort universitetssykehus i New York var etanol årsaken hos 45 av 125 pasienter innlagt med hypoglykemi. Innleggelse var nødvendig hos 31 av de 45 (6).

Imidlertid er det $\mathrm{i}$ en studie vist at omtrent halvparten av dem med etanolutløst hypoglykemi kan ha så lav promille ved måletidspunktet at mange ikke tas med i statistikken og at insidensen derfor blir tilsvarende usikker (7). De samme forfattere hevdet at alkoholindusert hypoglykemi har fått mye mindre oppmerksomhet i Europa enn i USA (7).

Hos barn kan selv små mengder utilsiktet tilført eller inntatt etanol gi hypoglykemi. Hypoglykemi er beskrevet etter alkoholvask av feberhet hud og etter svelging av alkoholholdig munnvask (7). I små kasuistikkbaserte undersøkelser har hypoglykemiforekomsten hos etanolintoksikerte barn vært angitt til mellom $10 \%$ og $24 \%$ (8), mens man i en annen retrospektiv undersøkelse fant en forekomst på 3,4 \% (9). Igjen er undersøkelsene vanskelig å sammenligne, siden etanolkonsentrasjonen kan ha falt så mye ved innleggelsestidspunktet at etanol ikke regnes med som årsak til hypoglykemien.

Hos voksne er det særlig kombinasjonen av tømte glykogenlagre og etanolinntak som dominerer (2). Trolig er denne kombinasjonen også viktig hos små barn, der glykogenlagrene tømmes mye raskere enn hos voksne.

Hos voksne kan glykogenlagrene tømmes under faste etter ca. 12 timer, men mye raskere ved økt forbruk, som ved hard fysisk aktivitet. Vår pasient hadde vært på skitur i syv timer, en fysisk anstrengende tur med mye klatring opp bakker og snowboardkjøring nedover.

Mekanismen har vært kjent lenge. Etanol hemmer glukoneogenesen (1). Omdanningen 
av etanol ved hjelp av enzymet alkoholdehydrogenase i levercellene krever mange molekyler av elektrontransportøren og koenzymet nikotinamid-adenin-dinukleotid $\left(\mathrm{NAD}^{+}\right)$. Så lenge det finnes etanol å metabolisere, vil ratioen redusert nikotinamid-adenin-dinukleotid (NADH)/NAD ${ }^{+}$være sterkt forhøyet. Det blir derfor en mangel på NAD ${ }^{+}$til andre reaksjoner, blant annet i glukoneogenesen.

$\mathrm{NAD}^{+}$brukes for eksempel av enzymet laktatdehydrogenase i omdanningen av laktat til pyruvat. Ved lavt $\mathrm{NAD}^{+}$-nivå faller pyruvatkonsentrasjonen, og nydanningen av sukker fra pyruvat blir så lav at blodglukosenivået synker. Også bruken av fett og aminosyrer til glukoneogenesen krever $\mathrm{NAD}^{+}$, og den blir mindre effektiv når etanolomdanningen legger beslag på så mye av dette koenzymet (10). Denne mekanismen er til stede selv ved lave etanolkonsentrasjoner (fig 1). I dyrestudier hemmes $47 \%$ av glukoneogenesen ved en etanolpromille på 0,1 (11). Det passer godt med en senere studie med fem friske frivillige menn, der glukoneogenesen ble redusert med $45 \%$ (12).

En annen mekanisme som kan resultere i hypoglykemi, er at etanol også øker nivået av et stoff som hemmer avlesningen av en rekke gener som er spesielt viktige i glukoneogenesen (13). En tredje årsak er at etanol øker blodsirkulasjonen gjennom de langerhanske øyer i pancreas på bekostning av den eksokrine delen, noe som kan føre til økt insulinsekresjon (14). Vi kjenner ikke til at noen har forsøkt å si hvilken av disse faktorene som har størst betydning for alkoholindusert hypoglykemi.

Vår pasient hadde en påfallende markert laktacidose, med verdier som vanligvis bare ses ved alvorlig septisk sjokk eller annen alvorlig sirkulasjonssvikt. Slike pasienter har i hovedsak vevshypoperfusjon, som gir type A-laktacidose. Laktacidoser som ikke skyldes vevshypoperfusjon, kalles lactacidose type B og skyldes ofte manglende omsetning av laktat intracellulært. Lactacidose type B ses blant annet ved metforminbehandling, vitamin $\mathrm{B}_{1}$ mangel og maligne hematologiske sykdommer (15). Alkoholutløst hypoglykemi er enda et eksempel på en type B-lactacidose. I mangel på $\mathrm{NAD}^{+}$omdanner ikke enzymet laktatdehydrogenase laktat til pyruvat raskt nok, og laktat hoper seg opp (1).

Siden laktatmålingene ble gjort på et mindre syre-base-apparat, kunne det også vært glykolsyre som ble målt, da disse apparatene feiltolker glykolsyre som laktat. Selv om vi tidligere har omtalt dette «laktatgapet», var ikke etylenglykolforgiftning med i vurderingene av denne pasienten (16). Metanolforgiftning hos alkoholpåvirkede med metabolsk acidose bør også vurderes.

Vi har så langt omtalt etanolutløst hypoglykemi. Det er et interessant spørsmål om forgiftninger med andre alkoholer, for eksempel etylenglykol eller metanol, også vil legge beslag på $\mathrm{NAD}^{+}$, lamme glukoneogenesen, gi hypoglykemi og samtidig en laktacidose. Dette er i så fall nok et forhold å vurdere $\mathrm{i}$ den ofte vanskelige utredningen av metabolske syre-base-forstyrrelser (16).

I flere av de amerikanske artiklene om alkoholindusert hypoglykemi antas det at tilstanden ofte ikke blir erkjent og av den grunn kan være underrapportert $(3,7)$. Selv om kombinasjonen hos vår pasient - faste, vodka og lang skitur - nok ikke kan anses som vanlig, er det imidlertid ikke uvanlig at alkoholinntak ledsages av minimalt eller manglende matinntak. Kanskje hypoglykemi står bak flere tilfeller av atypisk rus, aggresjon og bevissthetsforstyrrelser enn det som er rapportert?

Akuttmedisinens akronymer $\mathrm{ABC}$ er kjent. For noen har fortsettelsen DEFG Dont Ever Forget Glucose - vært huskeregelen, nettopp for aldri å glemme blodsukkermåling hos pasienter med nedsatt bevissthet. Det er lett å overse denne enkle undersøkelsen, spesielt der åpenbare faktorer er mer sannsynlig. Vi vet nå at kombinasjonen av faste og alkohol kan gi alvorlig hypoglykemi med cerebrale symptomer, noe som ikke må misoppfattes som alkoholrus.

Det er derfor viktig at man alltid forsikrer seg om at hypoglykemi ikke er årsak til bevissthetsforstyrrelser.

Pasienten har gitt samtykke til at artikkelen blir publisert.

\section{Trond Skjelstad (f. 1966)}

er anestesisykepleier og ambulansefagarbeider. Arbeider nå ved anestesiavdelingen og på deltid i ambulansetjenesten.

Forfatter har fylt ut ICMJE-skjemaet og oppgir ingen interessekonflikter.

\section{Marte Alsos Sørensen (f. 1980)}

er lege i spesialisering i anestesi. Forfatter har fylt ut ICMJE-skjemaet og oppgir ingen interessekonflikter.

\section{Erik Waage Nielsen (f. 1956)}

er overlege og professor.

Forfatter har fylt ut ICMJE-skjemaet og oppgir ingen interessekonflikter.

\section{Litteratur}

1. Steiner JL, Crowell KT, Lang CH. Impact of Alcoho on Glycemic Control and Insulin Action. Biomolecules 2015: 5: 2223-46.

2. Seltzer HS. Drug-induced hypoglycemia. A review of 1418 cases. Endocrinol Metab Clin North Am 1989; 18: 163-83.

3. Sporer KA, Ernst AA, Conte $R$ et al. The incidence of ethanol-induced hypoglycemia. Am J Emerg Med 1992; 10: 403-5.

4. Sucov A, Woolard RH. Ethanol-associated hypoglycemia is uncommon. Acad Emerg Med 1995; 2: $185-9$.

5. Lund C, Vallersnes OM, Jacobsen D et al. Outpatient treatment of acute poisonings in Oslo: poisoning pattern, factors associated with hospitalization, and mortality. Scand J Trauma Resusc Emerg Med 2012; 20: 1

6. Malouf R, Brust JC. Hypoglycemia: causes, neuro logical manifestations, and outcome. Ann Neurol 1985; 17: 421-30

7. Marks V, Teale JD. Drug-induced hypoglycemia Endocrinol Metab Clin North Am 1999; 28: 555- 77

8. Leung AK. Ethyl alcohol ingestion in children. A 15year review. Clin Pediatr (Phila) 1986; 25: 617-9.

9. Ernst AA, Jones K, Nick TG et al. Ethanol ingestion and related hypoglycemia in a pediatric and adolescent emergency department population. Acad Emerg Med 1996; 3: 46-9.

10. Madison LL, Lochner A, Wulff J. Ethanol-induced hypoglycemia. II. Mechanism of suppression of hepatic gluconeogenesis. Diabetes 1967: 16: 252-8.

11. Krebs HA, Freedland RA, Hems R et al. Inhibition of hepatic gluconeogenesis by ethanol. Biochem J 1969; 112: 117-24.

12. Siler SQ, Neese RA, Christiansen MP et al. The inhibition of gluconeogenesis following alcohol in humans. Am J Physiol 1998; 275: E897-907.

13. Tsai W-W, Matsumura S, Liu W et al. ATF3 mediates inhibitory effects of ethanol on hepatic gluconeogenesis. Proc Natl Acad Sci U S A 2015; 112: 2699-704.

14. Huang Z, Sjöholm A. Ethanol acutely stimulates islet blood flow, amplifies insulin secretion, and induces hypoglycemia via nitric oxide and vagally mediated mechanisms. Endocrinology 2008; 149 . 232-6

15. Ulvin OE, Nielsen EW. Unexplained severe lactic acidosis in emergency medicine. J Case Rep Stud 2013; 1: 202.

16. Salomonsen M, Hardersen R, Carlsson M et al. En mann i 70-årene funnet forvirret på treningstur. Tidsskr Nor Legeforen 2013; 133: 2483-7.

Mottatt 22.3. 2016, første revisjon innsendt 3.8. 2016, godkjent 21.12. 2016. Redaktør: Liv-Ellen Vangsnes. 